\title{
A Simulation Software for the Analysis of Cropping Systems in Livestock Farms
}

\author{
Luca Bechini*1, Andrea Di Guardo², Marco Botta², Salvatore Greco ${ }^{3}$, \\ Tommaso Maggiore ${ }^{1}$ \\ ${ }^{1}$ Dipartimento di Produzione Vegetale, Università di Milano, Via Celoria 2, 20133 Milano, Italy \\ ${ }^{2}$ Informatica Ambientale, Via Teodosio 13, 20131 Milano, Italy \\ ${ }^{3}$ Environmental Engineer, Milano, Italy
}

Received: 16 June 2008. Accepted: 22 September 2008.

\begin{abstract}
Simulation models can support quantitative and integrated analyses of agricultural systems. In this paper we describe VA.TE., a computer program developed to support the preparation and evaluation of nitrogen fertilising plans for livestock farms in the Lombardy region (northern Italy). The program integrates the cropping systems simulation model CropSyst with several regional agricultural databases, and provides the users with a simple framework for applying the model and interpreting results. VA.TE. makes good use of available data, integrating into a single relational database existing information about soils, climate, farms, animal breeds, crops and crop managements, and providing estimates of missing input variables. A simulation engine manages the entire simulation process: choice of farms to be simulated, model parameterisation, creation of model inputs, simulation of scenarios and analysis of model outputs. The program permits to apply at farm scale a model originally designed for the lower scale of homogeneous land parcel. It manages alternative simulation scenarios for each farm, helping to identify solutions to combine low nitrate losses and satisfactory crop yields. Example simulation results for three farms located on different soils and having varying levels of nitrogen surplus show that the integrated system (model + database) can manage various simulations automatically, and that strategies to improve $\mathrm{N}$ management can be refined by analysing the simulated amounts and temporal patterns of nitrogen leaching. We conclude by discussing the issues regarding the integration of existing regional databases with simulation models.
\end{abstract}

Key-words: Agricultural databases, agricultural systems, CropSyst, nitrate leaching, risk assessment, simulation models, water quality.

\section{Software availability}

Name of software: VA.TE. 1.0 (November 2004).

Design: Università di Milano, Dipartimento di Produzione Vegetale; Informatica Ambientale srl.

Development: Informatica Ambientale srl.

Contact address: Luca Bechini. E-mail address: luca.bechini@unimi.it.

Hardware and software required: Personal computer running Microsoft Windows 2000 Professional or later.

Programming language: Microsoft C\# and the .NET Framework 1.1.

\section{Introduction}

Agronomic simulation models, extensively developed and tested by researchers, represent a synthesis of knowledge and are reliable for the simulation of several processes. In the past years, model application has become increasingly important (Boote et al., 1996; Donatelli et al., 2002), in particular for studying the relations between agriculture and environment. Models can support strategic decisions, such as the definition of best crop management practices (e.g.
Acutis et al., 2000; Lewis et al., 2003) and the development of sustainable farming systems (e.g. Shaffer et al., 2000; Cabrera et al., 2005); they can also help to make within-season management decisions, as predicting crop yields (e.g. Bannayan et al., 2003) or evaluating replanting options (e.g. Heiniger et al., 1997). However, despite the relatively advanced development reached by developers, in many cases models are not routinely applied by users (advisors, extension specialists, farmers, decision 
makers). Problems, which may limit the adoption of models by users, include data availability (and their degree of completeness in terms of missing variables), database complexity, ease of use of the graphical user interface (GUI), size and format of input/output files.

In agricultural systems the identification of optimal management techniques for $\mathrm{N}$ fertilisers in the context of water protection from nitrate pollution and the estimation of nitrate loads to groundwater is a problem that can be effectively addressed with simulation models (e.g. Acutis et al., 2000). This is particularly important for livestock farms, where animal $\mathrm{N}$ load can be relevant (e.g. Sacco et al., 2003a; Bechini and Castoldi, 2006). Strategic decisions for the optimisation of $\mathrm{N}$ management are frequently taken using $\mathrm{N}$ balances (Grignani et al., 2003). However, $\mathrm{N}$ balances have several limitations: i) crop recovery of $\mathrm{N}$ applied with fertilisers varies with management and environmental conditions and it is difficult to predict, particularly for manures (Grignani et al., 2003); ii) it is difficult to estimate $\mathrm{N}$ losses and the variability of crop yields with varying levels of $\mathrm{N}$ fertilisation and other production factors, and under variable weather patterns.

Dynamic simulation models make it possible to quantify complex soil $\mathrm{x}$ plant $\mathrm{x}$ environment interactions that cannot be obtained neither experimentally (Meinke et al., 2001) nor with balances, and allow to determine the optimal dates and optimal fertiliser splitting strategies, which simple statistical models cannot do (Meynard et al., 2002). In particular, simulation models can be useful at two levels: i) advisors and consultants, who need to prepare or evaluate a fertilising plan for single farms, can benefit from the better understanding of the system provided by the model and integrate their knowledge with mechanistic estimates of $\mathrm{N}$ balance components; ii) public administrators and decision makers can carry out estimates of nitrate leaching for several farms at a time, thus considering large portions of a region and being able to identify the most critical farming and cropping systems. Specific software systems may automate as far as possible the collation of input data, run of simulation models and presentation of outputs, leaving the user to concentrate on those inputs and results that are most relevant to the specific problem. Crucial for these types of applications is the good integra- tion between the model and the database (Bechini and Stöckle, 2007). Many studies were carried out worldwide to integrate simulation models with geographical and alphanumerical databases. Some examples from Italy include the works of Basso et al. (2007), Bechini et al. (2003), Gardi (2001), Morari et al. (2004), Sacco et al. (2006) and Balderacchi et al. (2008).

With the purpose of providing a technical support for the agronomic analysis of $\mathrm{N}$ dynamics in crop rotations of livestock farms, in 20032004 we developed a software (called VA.TE.: "VAlutazioni TErritoriali dei PUA e dei PUAS in Regione Lombardia", which stands for "Regional evaluation of manure fertilising plans in Lombardy") which links databases of soils, climate, cropping systems and land use with a process-based, well-tested dynamic cropping systems simulation model (CropSyst; Stöckle et al., 2003). The software was developed with specific reference to the regional databases available in the Lombardy Region, northern Italy, one of the areas of Europe where the nitrate problem is most important, due to high livestock density (Regione Lombardia, 2004).

In this paper, we will: i) describe VA.TE.; ii) present a sample application; iii) discuss several aspects of the software design which can be of interest for similar projects, with particular reference to the use of available regional databases for simulation purposes.

\section{Materials and methods}

The general logical and functional software architecture is presented in Figure 1. It comprises several sub-systems with different functions: external data, internal database (the Complete Information Layer: CIL), simulation engine, simulation model, and user management. Existing data sources (databases of public administration and private users) represent external data before their incorporation into the software. In general, these data are not immediately suitable for model application, because individual data may be missing, specific variables might not be available in the original sources and relationships among different data sources may need to be established. Therefore, an internal database level is frequently needed: the CIL is a data structure with annexed importing modules whi- 


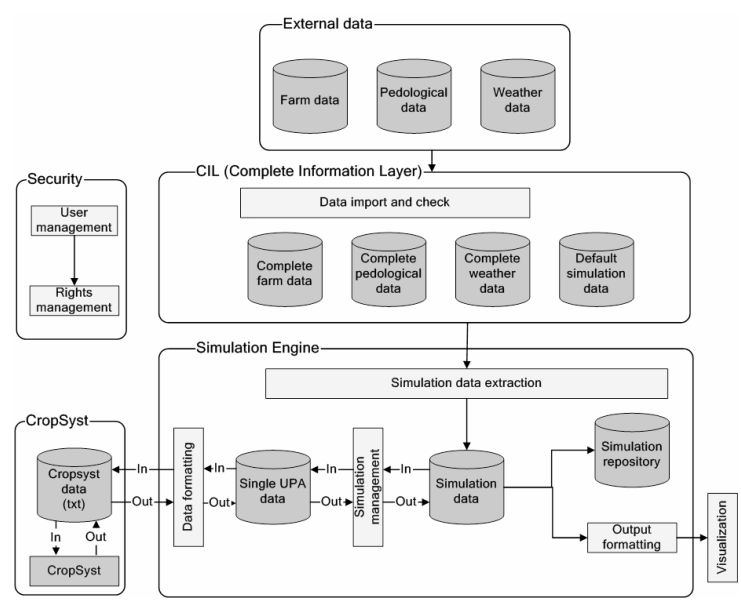

Figure 1. VA.TE. software architecture. Rectangles with rounded corners indicate sub-systems; each sub-system is composed of interacting modules. UPA, "Unità di Paesaggio Aziendale", standing for "Landscape Farm Unit".

ch analyse, complete and import external data. The simulation model represents the dynamic behaviour of crop and soil, and their interaction with atmosphere, by taking into account crop growth and development, soil water and $\mathrm{N}$ dynamics. Moreover, a simulation engine assists the user with the selection of the systems to analyse, extracts data from the CIL, prepares model inputs, runs the model, presents simulation outputs to the user and archives simulations to (and restores from) a dedicated repository. Finally, supporting features of user management may help in preserving data confidentiality or restricting access to specific software functions.

Details about these sub-systems are provided below, and will be further examined in the discussion section.

\section{External data}

Existing data sources for the plain of Lombardy are organised in separate relational databases, and include descriptions of livestock farms, climate and soils.

Information on livestock farms (crops, rotations, animal groups, manure production and use) is reported in the PUAs ("Piano di Utilizzazione Agronomica dei reflui zootecnici", standing for "agronomic fertilising plan with manures"). PUAs were introduced as obligatory plans for livestock farms of the Lombardy Region, as an implementation of the European Nitrates Directive, with the Regional Act 37/1993. PUAs are compiled by professional advisors and are evaluated, and eventually approved, by agronomists of the public administration. After approval, the farmer is authorized to apply manure on his farm fields (Provolo, 2005). In the PUA, the farm area is represented as a set of homogeneous farm blocks, called UPAs ("Unità di Paesaggio Aziendale", standing for "landscape farm units"), composed of one or more similar fields, cultivated with the same $\operatorname{crop}(\mathrm{s})$ and having the same soil type, the same climate and the same cultivation history. The cadastral parcels constituting each UPA are also indicated. In the PUA, the number of heads and the weight of animal groups are used to estimate the amount of manure- $\mathrm{N}$ available at farm level; for each crop of each UPA, the area occupied and the amounts of manure- $\mathrm{N}$ distributed are listed, together with the application dates.

Weather and pedological data were derived from a previous modelling project on pesticide leaching (Brenna et al., 2001). They include daily weather data (precipitation, maximum and minimum air temperatures) for 12 stations for a period of 11-13 years, and soil texture, $\mathrm{pH}$, cation exchange capacity, organic carbon and coarse content for each layer of representative soil profiles.

\section{Complete Information Layer}

The CIL is the relational database containing all the data needed to run simulations. Several steps are needed to load external data into the CIL. First, farm data are read and elaborated from the PUA database; in this step, using information on sowing and harvest dates, generic crop types provided in the PUAs are redefined to more specific categories, suitable for dynamic modelling. This means that maturity classes are used for maize and soybean in the CIL, instead of a generic indication of the crop species. Specification of maturity classes is particularly important for double cropping systems, as those made up of a winter cereal + maize, cultivated in a 12-month period.

However, the PUA database does not contain information about the crop rotations adopted. Cropsyst simulates a rotation, defined as the sequence of crops growing over the time on a land parcel, characterised by a uniform soil type, a certain atmospheric environment and a spatially homogeneous management for the en- 
tire parcel (Stöckle et al., 2003). As such, the concept of rotation can be applied at the spatial scale of the field or groups of similar fields, which in our particular case are represented by UPAs. For each UPA, we know from the PUA the average percentage assignment of the UPA area to different crops, but we do not know their exact sequence in time. To be able to carry out simulations for each UPA, a crop rotation needs to be identified at that scale. For this purpose, we developed a software component to create rotations for which the ratio of presence in time of different crops is (approximately) the same as the ratio of areas occupied by these crops. This processing, carried out when the simulation is prepared, is needed to ensure that the transfers of fertility (amounts of water, mineral $\mathrm{N}$, crop residues left in the soil) between the preceding and the successive crop are kept as close as possible to reality.

In addition, qualitative descriptions of animal manures included in the PUAs are used to calculate average farm-level manure properties (decomposition time constant, ammonium content), to be used in the dynamic simulation of manure decomposition. Finally, during the import phase an "actual scenario" is created, representing the information reported in the PUA.

Available daily weather data are imported and daily global radiation estimated on the basis of minimum and maximum daily air temperatures with the Campbell-Donatelli algorithm (Donatelli and Campbell, 1998; Donatelli et al., 2003), as applied by Ducco et al. (1998). The weather generator ClimGen (Stöckle et al., 2003) was applied to the available measured data, in order to provide 50-year synthetic series, which can be used to run longer simulations.

Available pedological data describe one or more representative soil profiles within a georeferenced soil unit (polygon); the percentage area of each profile within the unit is also indicated. Pedological data were imported only once and cannot be further modified; the pedotransfer functions proposed by Saxton et al. (1986) were applied to obtain a complete dataset for hydrological simulations. The digital cadastral map was not available and therefore it was not possible to automatically reference pedological and meteorological data to single UPAs. Because the only digital map available was that of administrative boundaries of muni- cipalities, and because it is known to which municipality each cadastral parcel belongs, it was decided to use the map of municipalities in order to: i) identify one reference weather station for each municipality (whose size was considered sufficiently small to be represented by one station only); ii) identify one or more soil units that are representative for each municipality, and indicate in the CIL their percentage area within each municipality. Subsequently, when configuring a simulation, the user may choose to make a run using the largest soil unit in the municipality, or to make a separate run for each soil unit and finally weight the results using the percentage area occupied by each unit.

The last remark about the data contained in the CIL is related to crop management. Since we neither found a regional database containing crop management practices (with the exception of manure storage and distribution described in the PUAs) nor identified a way of estimating this information from other existing data sources, we developed the crop management database, which contains detailed information about crop management operations for the entire crop cycle (sowing dates, tillage, fertilisation, irrigation and harvest). For each type of event, dates and specific parameters are included (e.g. amounts of $\mathrm{N}$ applied in $\mathrm{NH}_{4}, \mathrm{NO}_{3}$ and organic forms, type of fertiliser applied, application method); moreover, each event can be fully described with a label. To guarantee flexibility of parameterisation and use, we decided to hierarchically structure the database, by designing different spatial scales of management which are, from the highest to the lowest: the entire Lombardy region, the provinces, the municipalities and the farms. In the VA.TE. distribution, one set of management events is available for 31 crop types at the regional level and 10 sets are available for 10 provinces of the plain of Lombardy; these are stored as read-only information, and were obtained by interviewing experts. For each crop, the user can add one specific management set for each municipality and one or more sets for each farm. Each new set is created by automatically importing the set defined for the immediately higher scale as a template. When a new scenario is created, the system automatically selects, among the management sets in the database, the one available at the most detailed spatial scale. 


\section{Simulation engine}

The simulation engine manages the entire simulation, from the choice of farms until the presentation of model outputs. The outputs, including the most important simulated variables for crop and soil, are produced in the CropSyst's binary format (Universal Environmental Database) and converted into Microsoft Excel files. Detailed model outputs are summarised by calculating temporal statistics (for the multi-annual period) and spatial statistics (aggregating UPAs of each farm), which are then stored into an XML (Extensible Markup Language) file that describes the simulation. Simulations are of two types: standard simulations (available for the standard user), run with most default values (the user can modify only few default values, like the choice of farms/UPAs and the temporal detail of the outputs); advanced simulations, on the contrary, allow the user to modify most default input values if she/he has better information. Advanced simulations guarantee that the user's knowledge of specific farm characteristics can be incorporated into the simulations, overwriting default values proposed by the system. Also, in order to provide maximum flexibility, a single farm may be associated with more than one set of inputs. Each set defines a different farm scenario. Alternative scenarios can be compared to evaluate different management options. A scenario can be defined at farm and UPA levels. At farm level the user can associate the desired set of crop management operations to each crop of the farm; she/he can also change the amount of $\mathrm{N}$ applied with manure to each crop, setting it either to the value reported in the PUA or to a calculated value according to different rules (homogeneous partitioning over the farm, partitioning based on crop uptake), or even providing it manually. At the UPA level, the user can change the sequence of crops in the rotation, the dates of manure distribution, and the representative weather station and soil profile.

\section{CropSyst}

The simulation model used in VA.TE. is CropSyst (Stöckle et al., 2003), version 4.01.39. This mechanistic cropping systems model simulates crop growth and development, and associated water and $\mathrm{N}$ flows in the soil-crop system, with a daily time step, using inputs of daily weather, soil characteristics, crop morphological and physiological properties and crop management. CropSyst was chosen because it is a rather complete cropping systems model (based on a generic crop growth simulator, which can be parameterised for widely different crops), permits the definition of management events that mimic farmer's behaviour (tillage, fertilisation, irrigation, harvest), it is well documented, and it was applied, in Italy and abroad, for the simulation of crop growth and water and nitrogen dynamics. Applications in northern Italy include those on winter cereals, maize, and soybean by Donatelli et al. (1997), on maize, Italian ryegrass, winter wheat, meadows, sugar beet and soybean by Sacco et al. (2003b), on alfalfa by Confalonieri and Bechini (2004), on winter wheat by Bechini et al. (2006), and on rice by Confalonieri and Bocchi (2005) and Confalonieri et al. (2006). These research works confirmed model performance with regard to crop growth and development, soil water and inorganic nitrogen content.

In VA.TE., the CropSyst module queries the simulation database, creates model input files for each single UPA, runs the model and finally stores the results in the simulation database, where they are available for output (also in graphical form using CropSyst's output manager) and archiving.

\section{Use of the program}

The program is accessed with a GUI, which has four general buttons and a menu. The buttons allow to access basic functions: select UPAs to be simulated, prepare CropSyst's input files, run a simulation, analyse the results. The menu has the items "File", "CIL", "Tools" and "Help". The "File" menu allows to open an existing simulation, create a new one or exiting the program; with the "CIL" menu it is possible to view, modify or create instances of the crop management database (Fig. 2c), to import PUAs or weather data; the "Tools" menu allows to manage users and to restore/archive simulations; the "Help" menu opens the manual or an informative pop-up window. The simplest working session includes these steps: import one or more PUAs, create a new simulation (Fig. 2a), select relevant UPAs to be simulated (Fig. 2b), create CropSyst's input files, run the model, analyse the results (Fig. 2d). 
(a)

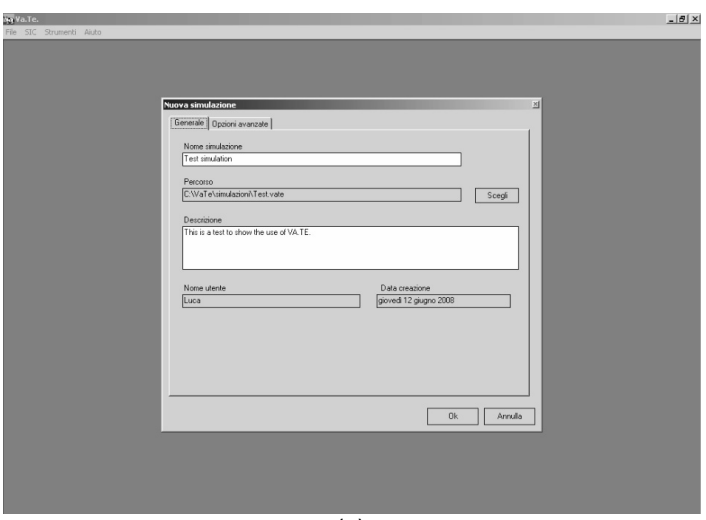

(c)

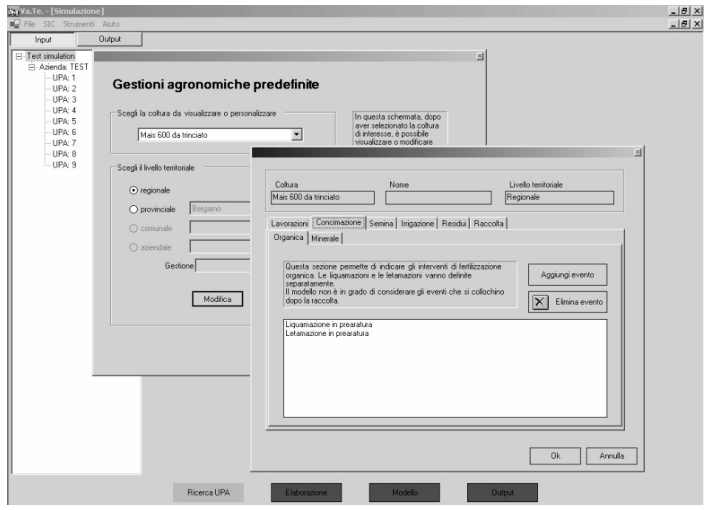

(b)

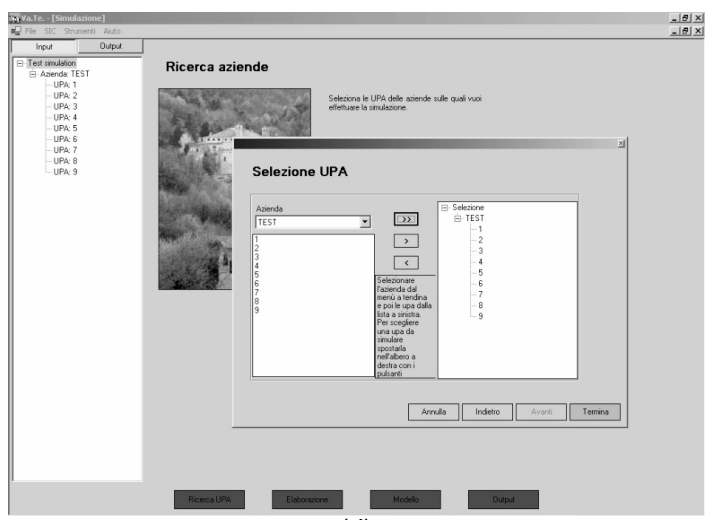

(d)

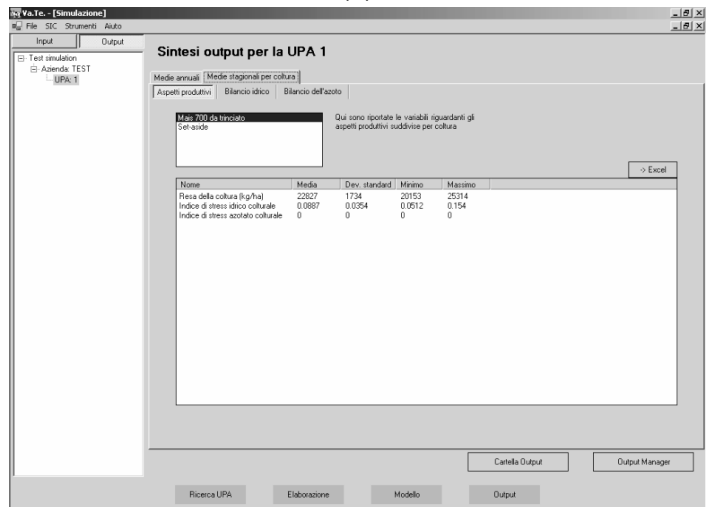

Figure 2. Screenshots of the program VA.TE.: (a) creation of a new simulation; (b) selection of the UPAs ("Unità di Paesaggio Aziendale", i.e. "Landscape Farm Units") to be simulated; (c) a view of the crop management database; (d) model outputs.

\section{Example simulations}

Simulations were run for three farms that differ for soil types, crops and animal $\mathrm{N}$ load (Tab. 1). All the farms lie within the area of one weather station only (Soresina, province of Cremona; $45^{\circ} 17^{\prime} \mathrm{N}$ lat.), characterised by an annual rainfall of $755 \mathrm{~mm}$ (with peaks in spring and autumn), and an average annual air temperature of $12.6{ }^{\circ} \mathrm{C}$. Soil types are Ultic Haplustalfs (Soil Survey Staff, 1998) for farms A and C, and Typic Dystrustepts for farm B (with high coarse content).

For the base scenario, province-level default crop management operations were used. Maize was sown at the beginning of April (or after May 10, if sown after Italian ryegrass); manure was applied in March before ploughing and in autumn after harvest. Italian ryegrass was sown in October and harvested for silage at the beginning of May; manure application was done before ploughing. Winter wheat was sown in Oc- tober and harvested at the end of June / beginning of July; manure was applied before ploughing. Meadows were cut five times per season (about every 35 days), starting at the half of May; manure applications were carried out after each cut. For the actual scenario mineral $\mathrm{N}$ fertiliser applications (only for maize and wheat) were parameterised as if crop recovery of manure- $\mathrm{N}$ was negligible (this extreme assumption can be made in farm practice as a safety measure to avoid crop $\mathrm{N}$ deficiencies). Therefore $\mathrm{N}$ applied with mineral fertilisers was set to $250 \mathrm{~kg} \mathrm{~N} \mathrm{ha}^{-1}$ for maize $(20 \%$ before sowing and $80 \% 35$ days after emergence) and $120 \mathrm{~kg}$ $\mathrm{N} \mathrm{ha}^{-1}$ for winter wheat $(10 \%$ on 20 November, $40 \%$ on 31 January and $50 \%$ on 30 April). Irrigation of maize and meadows was performed between 15 June and 15 August. The parameterisation of the automatic irrigation allowed to apply water only if at least $70 \%$ of the available soil water capacity was depleted; the amount 
Table 1. Description of the farms for the example simulations.

\begin{tabular}{|c|c|c|c|c|c|c|c|c|c|c|}
\hline \multirow[t]{2}{*}{ Farm } & \multirow{2}{*}{$\begin{array}{c}\text { AWC } \\
\mathrm{mm}\end{array}$} & \multirow{2}{*}{$\begin{array}{c}\text { Livestock } \\
\text { type }\end{array}$} & \multirow{2}{*}{$\begin{array}{c}\text { Animal N } \\
\text { load }\end{array}$} & \multirow{2}{*}{$\begin{array}{l}\text { Average } \\
\text { crop N } \\
\text { uptake } \\
\text { kg N ha }^{-1}\end{array}$} & \multirow{2}{*}{$\begin{array}{c}\text { Average } \\
\text { N surplus } \\
\end{array}$} & \multicolumn{5}{|c|}{ Percentage area of the farm cultivated with: } \\
\hline & & & & & & $\begin{array}{l}\text { Maize } \\
\text { (grain or } \\
\text { silage) }\end{array}$ & $\begin{array}{l}\text { Italian } \\
\text { ryegrass }+ \\
\text { Maize }\end{array}$ & $\begin{array}{l}\text { Winter } \\
\text { wheat }\end{array}$ & Meadows & Set-aside \\
\hline A & 258 & Pig & 264 & 262 & 2 & 95 & 0 & 0 & 0 & 5 \\
\hline B & 132 & Dairy & 266 & 265 & 1 & 0 & 43 & 0 & 57 & 0 \\
\hline $\mathrm{C}$ & 258 & Pig & 454 & 250 & 204 & 62 & 0 & 33 & 0 & 5 \\
\hline
\end{tabular}

AWC: average Available Water Capacity of soil profiles for the entire farm.

Average N surplus: calculated as (Animal N load) - (Average crop N uptake).

of irrigation water applied was a fixed amount of $110 \mathrm{~mm}$ in the case of the widely used surface irrigation system and of $1.2 \mathrm{~V}_{\text {refill }}$ in the case of sprinkler irrigation system, where $\mathrm{V}_{\text {refill }}$ is the amount of water needed to refill the soil up to field capacity. In both cases, the dates of irrigation events were constrained by the fixed frequency with which water is available for each farm (every 15 days).

Simulations were run for 50 years in order to consider weather variability. For each simulation, the average farm-level Apparent crop Nitrogen Recovery (ANR) and the nitrate concentration of drainage water (NCDW) were calculated from model outputs.

\section{Results}

Simulation results are summarised in Table 2. For the actual scenario, the average annual soil water drainage is an important component of the water balance, with the highest value occurring on the farm with the lowest available water capacity. Drainage is mainly driven by the inefficient surface irrigation system used in these farms: with this type of irrigation, the fixed amount of water applied is normally higher than what would be strictly needed to refill the soil to field capacity. As shown in Figure 3, drainage and leaching occur mainly in July, shortly after the start of the irrigation period, and in autumn. Nitrate leaching varies among farms (Tab. 2 ), depending on $\mathrm{N}$ surplus, use of mineral $\mathrm{N}$ fertilisers and crop/soil combinations. Farm C has the highest leaching, because it associates a relevant animal $\mathrm{N}$ load with intense use of mineral $\mathrm{N}$ fertilisers. The temporal variability of these values is consistent (Tab. 2 and Fig. 3).
We evaluated alternative management scenarios, aimed at reducing nitrate leaching and maintaining good crop yields. We first evaluated the reduction of the use of mineral $\mathrm{N}$ fertilisers on maize and wheat (MR scenario). As shown in Table 2, MR is a good strategy, because in general leaching and its variability among years decreased, ANR increased, and NCDW decreased, still maintaining crop yields similar to the actual scenario. For the most intensive farm $C$, the MR scenario was not sufficient to reach a NCDW lower than the European drinking water guide level of $11.3 \mathrm{mg} \mathrm{N} \mathrm{L}^{-1}$, even if nitrate leaching was strongly reduced compared to the actual scenario. To further optimise $\mathrm{N}$ management in farm $\mathrm{C}$, we evaluated two other scenarios: the use of the more efficient sprinkler irrigation system (SP scenario), and the combination of mineral $\mathrm{N}$ fertiliser reduction with sprinkler irrigation (RS scenario). The comparison of the actual and SP scenarios for farm C

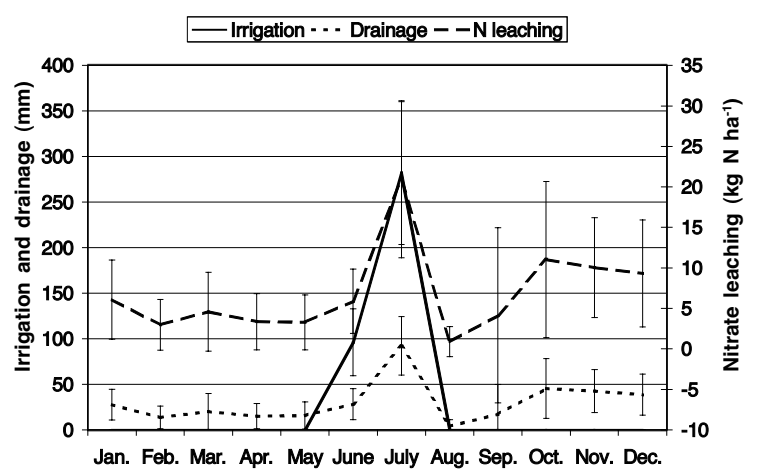

Figure 3. Average results of the multi-annual simulation of continuous maize on farm A under the actual scenario (manure and mineral fertilisers are used; surface irrigation system). Standard deviations among years are indicated with the vertical bars. 
Bechini L., Di Guardo A., Botta M., Greco S., Maggiore T.

Table 2. Average and standard deviation (in brackets) of simulation results obtained for the multi-annual simulation period.

\begin{tabular}{|c|c|c|c|c|c|c|c|c|c|c|c|c|c|}
\hline \multirow[t]{3}{*}{ Farm } & \multirow[t]{3}{*}{ Scenario } & \multirow{2}{*}{\multicolumn{2}{|c|}{$\begin{array}{c}\mathrm{N} \\
\text { leaching }\end{array}$}} & \multirow{2}{*}{\multicolumn{2}{|c|}{ Drainage }} & \multicolumn{6}{|c|}{ Simulated crop yields (dry wt.) } & \multirow[t]{2}{*}{ ANR } & \multirow[t]{2}{*}{ NCDW } \\
\hline & & & & & & \multicolumn{2}{|c|}{$\begin{array}{l}\text { Maize } \\
\text { (grain) }\end{array}$} & \multicolumn{2}{|c|}{$\begin{array}{l}\text { Silage maize } \\
\text { (entire plant) }\end{array}$} & \multicolumn{2}{|c|}{$\begin{array}{c}\text { Winter wheat } \\
\text { (grain) }\end{array}$} & & \\
\hline & & $\mathrm{kg}$ & $\mathrm{ha}^{-1}$ & & $\mathrm{~m}$ & & & $-\mathrm{t}$ & -1 & & - & $\mathrm{kg} \mathrm{N} \mathrm{kg}^{-1} \mathrm{~N}$ & $\operatorname{mg~N~L} \mathrm{N}^{-1}$ \\
\hline $\mathrm{A}$ & Actual & 82 & (34) & 360 & $(86)$ & 14.2 & $(0.8)$ & - & & - & - & 0.68 & 23 \\
\hline $\mathrm{B}$ & Actual & 34 & $(8)$ & 578 & $(180)$ & - & - & 21.1 & $(1.5)$ & - & - & 0.66 & 6 \\
\hline $\mathrm{C}$ & Actual & 204 & $(83)$ & 320 & $(81)$ & 14.2 & $(0.8)$ & - & - & 6.8 & $(1.7)$ & 0.47 & 64 \\
\hline $\mathrm{A}$ & MR & 14 & (9) & 360 & $(86)$ & 14.2 & $(0.8)$ & - & - & - & - & 0.80 & 4 \\
\hline B & MR & 31 & (7) & 601 & (155) & - & - & 21.1 & (1.4) & - & - & 0.65 & 5 \\
\hline $\mathrm{C}$ & MR & 116 & (49) & 321 & (81) & 13.5 & (1.8) & - & - & 6.8 & (1.7) & 0.54 & 36 \\
\hline $\mathrm{C}$ & SP & 203 & (99) & 244 & (78) & 14.1 & (0.8) & - & - & 6.8 & $(1.7)$ & 0.47 & 83 \\
\hline $\mathrm{C}$ & $\mathrm{RS}$ & 118 & (54) & 245 & (78) & 13.5 & (1.8) & - & - & 6.8 & (1.7) & 0.54 & 48 \\
\hline $\mathrm{C}$ & M0 & 51 & (23) & 273 & (79) & 12.6 & (3.9) & - & - & 6.8 & (1.7) & 0.61 & 19 \\
\hline
\end{tabular}

ANR, Apparent crop Nitrogen Recovery.

NCDW, Nitrate-N Concentration of Drainage Water.

$\mathrm{MR}$, reduced mineral $\mathrm{N}$ fertilisation on maize and wheat.

SP, use of the sprinkler irrigation system.

$\mathrm{RS}$, combination of MR and SP scenarios.

$\mathrm{M} 0$, cessation of mineral $\mathrm{N}$ fertilisation on maize and wheat.

(Tab. 2) indicates that, even if under the sprinkler irrigation the drainage is reduced, nitrate leaching remains at the same level of the actual scenario. This happens because (data not shown) summer leaching events and annual drainage are reduced (due to the more efficient irrigation system), but excess nitrate remaining in the soil after harvest is leached in autumn. Therefore the total annual leaching remains unchanged and NCDW increases. Similarly, summer leaching and drainage are reduced in RS compared to MR, and NCDW increases. We finally evaluated a scenario for farm C (M0), involving the cessation of mineral $\mathrm{N}$ fertilisers application, and using a sprinkler irrigation system. In this case (Tab. 2) $\mathrm{N}$ leaching is strongly reduced and ANR is increased. This shows that on this farm manure alone is sufficient to provide reasonable crop yields, even if lower and more variable than in the actual scenario.

\section{Discussion and conclusions}

\section{Utility of the integrated system}

The example simulations show that VA.TE. is a useful tool to run multiple simulations for one or more farms. For each simulation the long, tedious and error-prone work of input files preparation was carried out by VA.TE., which built: a soil file by identifying and processing the relevant pedological information; a management file by identifying all information from the crop management database; a crop rotation file as described before; a simulation file that links all the input files together and specifies the duration of the simulation. Moreover, VA.TE. has run all the simulations without user's interaction, and extracted relevant results in order to calculate aggregated model outputs (e.g. farmlevel weighted averages for the multi-annual simulation period). If this work had to be carried out without an integrated database-model system, the time required would have been much longer.

The example simulations demonstrate that, compared to static $\mathrm{N}$ balances, a dynamic simulation model has more capabilities, because it integrates the effects of irrigation system, climate, soil hydrological properties and their interactions in the estimation of $\mathrm{N}$ losses, and provides dynamic results of the variables simulated.

Issues related to the design of the integrated system

Several aspects of the integration of the existing regional databases with the simulation model are worth to be discussed in detail, as they can be of interest in similar projects. The regional databases that we included in VA.TE. had not 
Table 3. Statistics of 50-yr simulation of nitrate leaching for three rotations and two different sequences of the same crops.

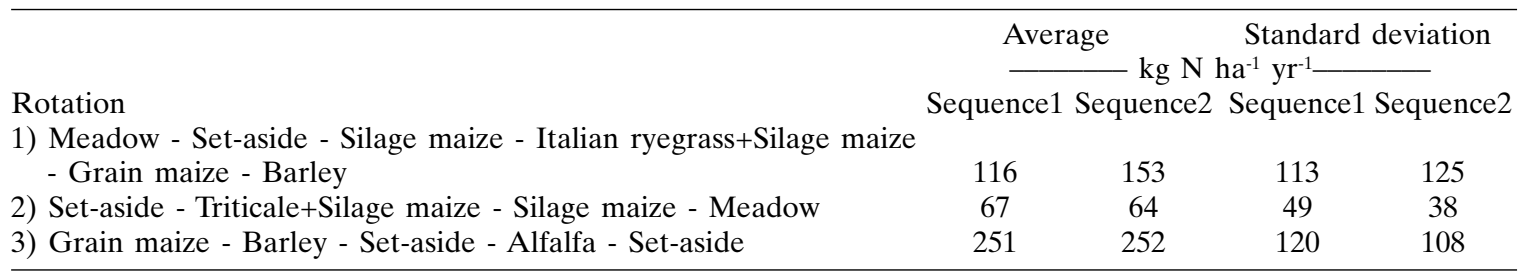

been developed for modelling applications. Therefore, relevant design efforts were done in VA.TE. to ensure a good link between these databases and the simulation model. The issues that we dealt with during the integration can be classified as: i) estimation of variables that were missing in the original databases, using other variables available in these database at the same spatial or temporal scale; ii) estimation of missing variables, using variables at different scales; iii) introduction in the database of new variables that could not be estimated from information contained in external data sources.

The first issue (estimation of missing variables using variables available at the same scale) is a step taken in most regional-scale modelling studies. It includes the estimation of soil hydraulic properties using pedotransfer functions, the estimation of global solar radiation based on simpler weather data, and weather generation. These estimations introduce uncertainty in the modelling process (Bellocchi et al., 2003; Gijsman et al., 2002), but are needed when models are applied at large scales.

The second issue (estimation of missing variables, using variables that are available at different scales) includes various aspects. One aspect is the construction of a crop rotation (sequence) from the average percentage assignment of the UPA area to different crops. To carry out this task we designed a software component that makes use of existing information. However, a degree of subjectivity is present he$\mathrm{re}$, as the component generates only one out of multiple sequences that are possible when more than two crops are present. To give an example of such uncertainty, we compared the average and the standard deviation of annual nitrate leaching simulated using two different sequences in time for three rotations. The results (Tab. 3) show that in one case (rotation 1) the statistics of nitrate leaching can be substantially different, suggesting that, for UPAs contai- ning many different crops, uncertainty about their sequence in time may generate uncertainty in the simulated results.

Another aspect is the selection of the soil unit to be used in the simulation: as mentioned above, more than one representative soil profile and soil unit may be referred to the municipality where an individual UPA lies. To deal with this uncertainty, the fastest solution is to run one simulation only, using the soil profile that covers most of the area. The other solution is to run simulations on all soil profiles attached to that municipality, and then describe the statistical distribution of the results. To evaluate this issue with an example, we compared the two solutions when simulating a continuous rotation of grain maize in a municipality containing three extremely heterogeneous soil types (with field capacity ranging from 0.07 to $0.23 \mathrm{~m}^{3}$ $\mathrm{m}^{-3}$ ). In the first case (one simulation is run on the soil profile that covers most of the area) the average nitrate leaching was $210 \mathrm{~kg} \mathrm{~N} \mathrm{ha}^{-1} \mathrm{yr}^{-1}$, while it was 238 in the second case, when a soil rich in coarse materials was included. Also this example shows the importance of the uncertainty of available inputs.

Similarly, the selection of the weather station is important, because Rivington et al. (2006) showed that uncertainty of weather data might impact on the uncertainty of simulated results. The simple solution adopted in VA.TE. (i.e. assume that a municipality can be described using data from one weather station only) is justified by the relatively small size of municipalities compared to the area covered by the 12 stations used. For example, the largest municipality of the weather region of Cavriana covers only $6 \%$ of the area of its weather region; in many more cases the percentage area covered by individual municipalities is much lower.

Until now we have described how existing variables were used to estimate other variables that were not included in the original databa- 
ses. For crop management, however, we were neither able to find information in regional databases nor to estimate it from existing data. We therefore developed the crop management database, described above. This data structure has the advantage of providing default values at large scales (region / provinces) for the standard user, still allowing advanced user to precisely describe crop management for specific portions of the region (the municipalities) or for specific farms which substantially differ from the wider upper scales, therefore taking into account soil type, topography and climate.

The final result is that, by carefully designing the entity-relationship data model for the CIL, we obtained an open, flexible and expandable database, to which entities and data for different applications can be easily added, and which can be used in future developments of VA.TE. as well as in other applications (being a stand-alone Microsoft Access file, the CIL can be easily used outside VA.TE.). For example, to run a pesticide leaching model, entities containing specific information on herbicide, fungicide and insecticide spraying should be included, while the rest of agronomic, meteorological and pedological information would be already available, structured, updateable and linked with the original data sources.

\section{Acknowledgments}

This research project was funded by Regione Lombardia (Italy) and by Università degli Studi di Milano (Italy). Claudio O. Stöckle and Roger Nelson (Washington State University, Department of Biological Systems Engineering, Pullman, Washington, USA) provided substantial and continuous support about CropSyst. We acknowledge the scientific support of the Ente Regionale di Sviluppo Agricolo e Forestale (ERSAF - Regione Lombardia), for critically discussing the type of weather and pedological data to be used and for providing them, and the fruitful discussions with program users during the design of VA.TE. Roberto Confalonieri (JRC, Ispra, Italy) and Carlo Giupponi (University of Venice, Italy) provided useful comments on a previous version of this paper.

\section{References}

Acutis M., Ducco G., Grignani C. 2000. Stochastic use of LEACHN model to forecast nitrate leaching in different maize cropping systems. European Journal of Agronomy, 13:191-206.
Balderacchi M., Di Guardo A., Vischetti C., Trevisan M. 2008. The Effect of Crop Rotation on Pesticide Leaching in a Regional Pesticide Risk Assessment. Environmental Science and Technology, In press. doi: $10.1021 / \mathrm{es} 801287 \mathrm{w}$.

Bannayan M., Crout N.M.J., Hogenboom G. 2003. Application of the CERES-Wheat model for within-season prediction of winter wheat yield in the United Kingdom. Agronomy Journal, 95:114-125.

Basso B., Bertocco M., Sartori L., Martin E.C. 2007. Analyzing the effects of climate variability on spatial pattern of yield in a maize-wheat-soybean rotation. European Journal of Agronomy, 26:82-91.

Bechini L., Castoldi N. 2006. Calculating the soil surface nitrogen balance at regional scale: example application and critical evaluation of tools and data. Italian Journal of Agronomy / Rivista di Agronomia, 1:665-676.

Bechini L., Stöckle C.O. 2007. Integration of a cropping systems simulation model and a relational database for simple farm-scale analyses. Agronomy Journal, 99:1226-1237.

Bechini L., Bocchi S., Maggiore T. 2003. Spatial interpolation of soil physical properties for irrigation planning. A simulation study in Northern Italy. European Journal of Agronomy, 19:1-14.

Bechini L., Bocchi S., Maggiore T., Confalonieri R. 2006. Parameterization of a crop growth and development simulation model at sub-model components level. An example for winter wheat (Triticum aestivum L.). Environmental Modelling \& Software, 21:1042-1054.

Bellocchi G., Donatelli M., Fila G. 2003. Evaluation of estimated radiation data for calculating evapotranspiration and crop biomass. Italian Journal of Agronomy, 7:95-102.

Boote K.J., Jones J.W., Pickering N.B. 1996. Potential uses and limitations of crop models. Agronomy Journal, 88:704-716.

Brenna S., Riparbelli C., Capri E., Trevisan M., Auteri D., Gusmeroli S. 2001. SuSAP: a decision support system for a sustainable use of pesticides in agriculture. (In Italian), 211-212. In: Bindi M., Donatelli M., Porter J., Van Ittersum M.K. (eds.): $2^{\text {nd }}$ International Symposium «Modelling Cropping Systems», European Society for Agronomy, 16-18 July 2001, Florence, Italy, 211-212.

Cabrera V.E., Breuer N.E., Hildebrand P.E., Letson D. 2005. The dynamic North Florida dairy farm model: A user-friendly computerized tool for increasing profits while minimizing $\mathrm{N}$ leaching under varying climatic conditions. Computers and Electronics in Agriculture, 49:286-308.

Confalonieri R., Bechini L. 2004. A preliminary evaluation of the simulation model CropSyst for alfalfa. European Journal of Agronomy, 21:223-237.

Confalonieri R., Bocchi S. 2005. Evaluation of CropSyst for simulating the yield of flooded rice in northern Italy. European Journal of Agronomy, 23:315-326. 
Confalonieri R., Gusberti D., Bocchi S., Acutis M. 2006. The CropSyst model to simulate the $\mathrm{N}$ balance of rice for alternative management. Agronomy for Sustainable Development, 26:241-249.

Donatelli M., Campbell G.S. 1998. A simple model to estimate global solar radiation. In: Zima M., Bartošová M.L. (eds.): Proceedings of the $5^{\text {th }}$ ESA Congress, 28 June - 2 July 1998, Nitra, Slovakia, Slovak Agricultural University, Nitra, 133-134.

Donatelli M., Bellocchi G., Fontana F. 2003. RadEst3.00: Software to estimate daily radiation data from commonly available meteorological variables. European Journal of Agronomy, 18:363-367.

Donatelli M., Stöckle C.O., Ceotto E., Rinaldi M. 1997. Evaluation of CropSyst for cropping systems at two locations of northern and southern Italy. European Journal of Agronomy, 6:35-45.

Donatelli M., Van Ittersum M.K., Bindi M., Porter J.R. 2002. Modelling cropping systems - highlights of the symposium and preface to the special issues. European Journal of Agronomy, 18:1-11.

Ducco G., Bechini L., Donatelli M., Marletto V. 1998. Estimation and spatial interpolation of global solar radiation in the Po valley, Italy, In: Zima M., Bartošová M.L. (eds.): Proceedings of the $5^{\text {th }}$ ESA Congress, 28 June - 2 July 1998, Nitra, Slovakia, Slovak Agricultural University, Nitra, pp. 139-140.

Gardi C. 2001. Land use, agronomic management and water quality in a small Northern Italian watershed. Agriculture, Ecosystems and Environment, 87:1-12.

Gijsman A.J., Jagtap S.S., Jones J.W. 2002. Wading through a swamp of complete confusion: how to choose a method for estimating soil water retention parameters for crop models. European Journal of Agronomy, 18:75-105.

Grignani C., Bassanino M., Sacco D., Zavattaro L. 2003. Il bilancio degli elementi nutritivi per la redazione dei piani di concimazione. Rivista di Agronomia, 37:155-172.

Heiniger R.W., Vanderlip R.L., Williams J.R., Welch S.M. 1997. Developing guidelines for replanting grain sorghum: III. Using a plant growth model to determine replanting options. Agronomy Journal, 89:93-100.

Lewis D.R., McGechan M.B., McTaggart I.P. 2003. Simulating field-scale nitrogen management scenarios involving fertilizer and slurry applications. Agricultural Systems, 76:159-180.

Meinke H., Baethgen W.E., Carberry P.S., Donatelli M., Hammer G.L., Selvaraju R., Stöckle C.O. 2001. Increasing profits and reducing risks in crop production using participatory systems simulation approaches. Agricultural Systems, 70:493-513.

Meynard J.M., Cerf M., Guichard L., Jeuffroy M.H., Makowski D. 2002. Which decision support tools for the environmental management of nitrogen? Agronomie, 22:817-829.

Morari F., Lugato E., Borin M. 2004. An integrated nonpoint source model-GIS system for selecting criteria of best management practices in the Po Valley, North Italy. Agriculture, Ecosystems and Environment, 102:247-262.

Provolo G. 2005. Manure management practices in Lombardy (Italy). Bioresource Technology, 96:145-152.

Regione Lombardia. 2004. Programma di Tutela e Uso delle Acque, Allegato 7 - Stima dei carichi effettivi di azoto e fosforo da agricoltura nelle acque di superficie. Regione Lombardia, Milano, Italy.

Rivington M., Matthews K.B., Bellocchi G., Buchan K. 2006. Evaluating uncertainty introduced to processbased simulation model estimates by alternative sources of meteorological data. Agricultural Systems, 88:451-471.

Sacco D., Bassanino M., Grignani C. 2003a. Developing a regional agronomic information system for estimating nutrient balances at a larger scale. European Journal of Agronomy, 20:199-210.

Sacco D., Grignani C., Marchetti R., Ceotto E., Ponzoni G., Berti A., Borin M., Morari F., Lugato E. 2003b. Qualità ambientale e gestione dei reflui zootecnici. Risultati di una ricerca collegiale in pianura padana. In: Mori M., Fagnano M. (eds.): Proceedings of the $35^{\text {th }}$ Congress of the Italian Society for Agronomy, 1618 September 2003, Naples, 11-12.

Sacco D., Zavattaro L., Grignani C. 2006. Regional-scale Predictions of Agricultural N Losses in an Area with a High Livestock Density. Italian Journal of Agronomy / Rivista di Agronomia, 1:689-703.

Saxton K.E., Rawls W.J., Romberger J.S., Papendick R.I. 1986. Estimating generalized soil-water characteristics from texture. Soil Science Society of America Journal, 50:1031-1036.

Shaffer M.J., Bartling P.N.S., Ascough II J.C. 2000. Object-oriented simulation of integrated whole farms: GPFARM framework. Computers and Electronics in Agriculture, 28:29-49.

Soil Survey Staff. 1998. Keys to Soil Taxonomy. $8^{\text {th }}$ ed. U.S. Gov. Print. Office, Washington, DC.

Stöckle C.O., Donatelli M., Nelson R. 2003. CropSyst, a cropping systems simulation model. European Journal of Agronomy, 18:289-307. 